\title{
Correction of skeletal class II severe open bite with temporomandibular joint disorder treated by miniscrew anchorage and molar extraction: a case report
}

Masato Kaku* (D, Taeko Yamamoto, Yuka Yashima, Jin Izumino, Haruka Kagawa, Kazutaka Ikeda and Kotaro Tanimoto

\begin{abstract}
Background: Little information is available on the treatment of open bite with temporomandibular joint disorder by intrusion of molars using miniscrews.

Case presentation: This case report describes a 42-year-old Japanese woman with a skeletal class II severe anterior open bite and temporomandibular joint disorder. The pretreatment magnetic resonance imaging of both temporomandibular joints revealed osteoarthritis and anterior disc displacement without reduction in both temporomandibular joints. A stabilization splint was used before orthodontic treatment and bilateral upper and lower premolars were extracted. Miniscrews were inserted into the palatal region to intrude the maxillary molars and avoid loss of anchorage. The maxillary left first molar was also extracted to improve the molar relationship and the dental midline. Normal overjet and overbite with Angle class I molar relationship were achieved, and the upper and lower midlines coincided. Our patient's teeth continued to be stable and her temporomandibular joint was asymptomatic after a retention period of 2 years.
\end{abstract}

Conclusions: Intrusion of molars by miniscrews is available for skeletal class II severe open bite.

Keywords: Open bite, Skeletal class II, Steep mandible, TMD, DDwoR, Stabilization splint, Orthodontic treatment, Miniscrew

\section{Background}

Temporomandibular joint disorder (TMD) is a comprehensive term and is characterized by the clinical presentation of: pain in the masticatory musculature and in the temporomandibular joint (TMJ), limited range of mandibular movement, and clicking or crepitus during jaw movement [1]. The etiology of TMD is suggested to be multifactorial, with malocclusion being a potential risk factor [2]. Numerous treatment methods have been described for anterior disc displacement without reduction (DDwoR) of TMJ. Among them, orthodontic treatment along with an occlusal splint is considered quite effective for managing TMD with anterior disc displacement [3].

\footnotetext{
* Correspondence: mkaku@hiroshima-u.ac.jp

Department of Orthodontics and Craniofacial Developmental Biology,

Hiroshima University Graduate School of Biomedical and Health Sciences,

1-2-3 Kasumi, Minami-ku, Hiroshima 734-8553, Japan
}

In open bite cases, overgrowth of the maxillary and mandibular posterior dentoalveolar heights is often observed $[4,5]$, and cases of skeletal class II open bite with a steep mandible are more difficult to treat because of the increased vertical facial height [6, 7]. Therefore, high-pull headgear with a transpalatal arch [8] is traditionally used to correct the over-erupted posterior molar regions. However, this approach of reducing the posterior dentoalveolar height using headgear is not always effective as the treatment outcome is greatly influenced by the patient's cooperation. Therefore, nowadays, miniplate [9-12] and miniscrews [13-18] are used currently for absolute anchorage. Cases of anterior open bite are often associated with TMD, and only a few reports describe the management of open bite and TMD by molar intrusion using miniscrew anchorage [19-22].

(c) The Author(s). 2019 Open Access This article is distributed under the terms of the Creative Commons Attribution 4.0 International License (http://creativecommons.org/licenses/by/4.0/), which permits unrestricted use, distribution, and reproduction in any medium, provided you give appropriate credit to the original author(s) and the source, provide a link to the Creative Commons license, and indicate if changes were made. The Creative Commons Public Domain Dedication waiver (http://creativecommons.org/publicdomain/zero/1.0/) applies to the data made available in this article, unless otherwise stated. 
In this case report, we describe the outcome of severe skeletal class II open bite treated using miniscrews along with extraction of the four premolars and the left maxillary first molar.

\section{Case presentation}

\section{Pretreatment evaluation}

Our patient, a Japanese woman aged 42 years and 6 months, visited our dental hospital with a chief complaint of impaired masticatory function due to anterior open bite. She also experienced pain in the TMJ while chewing and mouth opening. Her open bite had worsened gradually and she also had tongue thrust. She was previously recommended orthodontic treatment with orthognathic surgery by an orthodontist, but she did not want to undergo the surgery.

Her pretreatment facial appearance revealed a convex profile, and suggested hypermentalis activity associated with lip closure. The initial intraoral photographs revealed a $-6.0-\mathrm{mm}$ anterior open bite and occlusal contact between only the second molars. The right molar occlusal relationship was class II, while that of the left was a more severe type of class II. There was crowding in either arch and the upper dental midline had shifted to the right by $4 \mathrm{~mm}$. The lower midline coincided with the facial midline (Figs. 1 and 2). A panoramic radiograph revealed the existence of three third molars except the upper right third molar (Fig. 3). A severe skeletal class II relationship of angle of point A-nasion-point B (ANB), $11.5^{\circ}$ and a steep Frankfort-mandibular plane angle (FMA, $47.5^{\circ}$ ) with lingual inclination of upper incisors of upper incisor-Frankfort plane angle (U1-FH), $104.6^{\circ}$ was noted in the cephalometric measurements (Table 1). The DDwoR of both TMJs was evident in the magnetic resonance imaging (MRI) images (Fig. 4a, b). Schüller's view showed flattening of both condyles, but there was no restriction of jaw movement (Fig. 5a, b). Based on this information, our patient was diagnosed to have a skeletal class II open bite with TMD. Informed consent was obtained from all individual participants included in the study.

\section{Treatment plan}

A stabilization occlusal splint was used before the orthodontic treatment to reduce the TMJ pain on masticatory movement. Because our patient refused surgical treatment, it was decided to correct the anterior open bite and achieve an ideal occlusion with class I molar relationship via orthodontic treatment alone (without orthognathic surgery). The treatment plan was as follows.

1. Extraction of the maxillary right and left first premolars

2. Extraction of the mandibular right and left second premolars.

3. Insertion of miniscrews into the palatal region and left alveolar bone of mesial part of first molars to intrude the maxillary molars and to avoid anchorage loss.

4. Correction of crowding and distal movement of anterior teeth.

5. Extraction of the maxillary left first molar to correct the midline and left molar relationship.

6. Preparation and insertion of a retainer with tongue crib to avoid tongue thrust.

\section{Treatment progress}

Before the orthodontic treatment, a stabilization occlusal splint was placed for 3 months to reduce the TMJ pain. After our patient confirmed alleviation of TMD symptoms, the four premolars were extracted and 0.018-inch $(0.457-\mathrm{mm})$ standard edgewise brackets were bonded on the maxillary and mandibular teeth. This was followed by placement of two self-drilling titanium alloy miniscrews $(2.0 \mathrm{~mm}$ in diameter and $6 \mathrm{~mm}$ in length, Dual

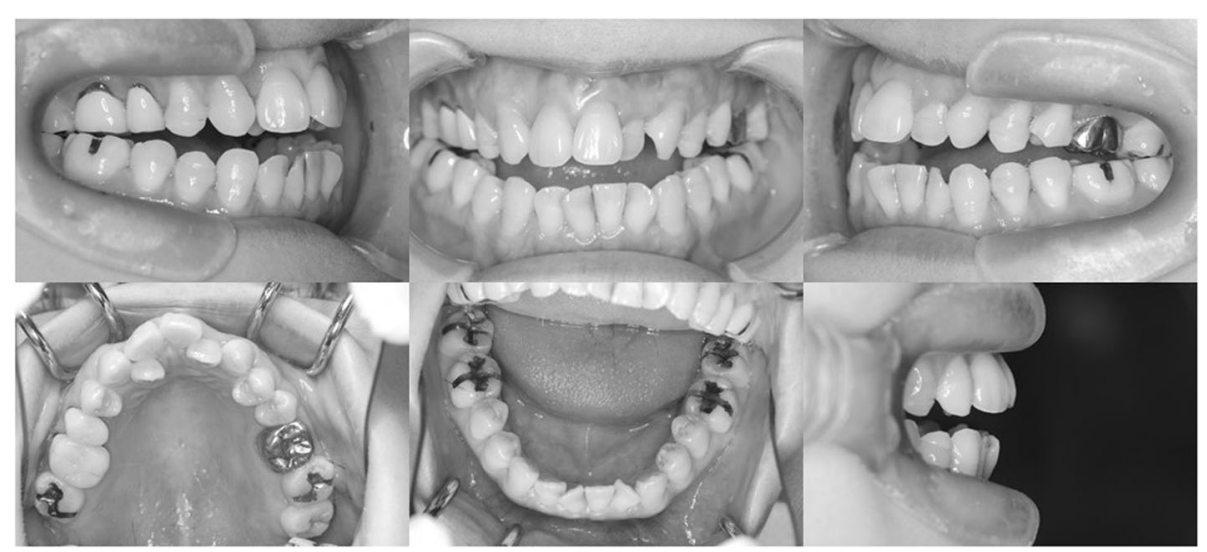

Fig. 1 Pretreatment intraoral photographs 

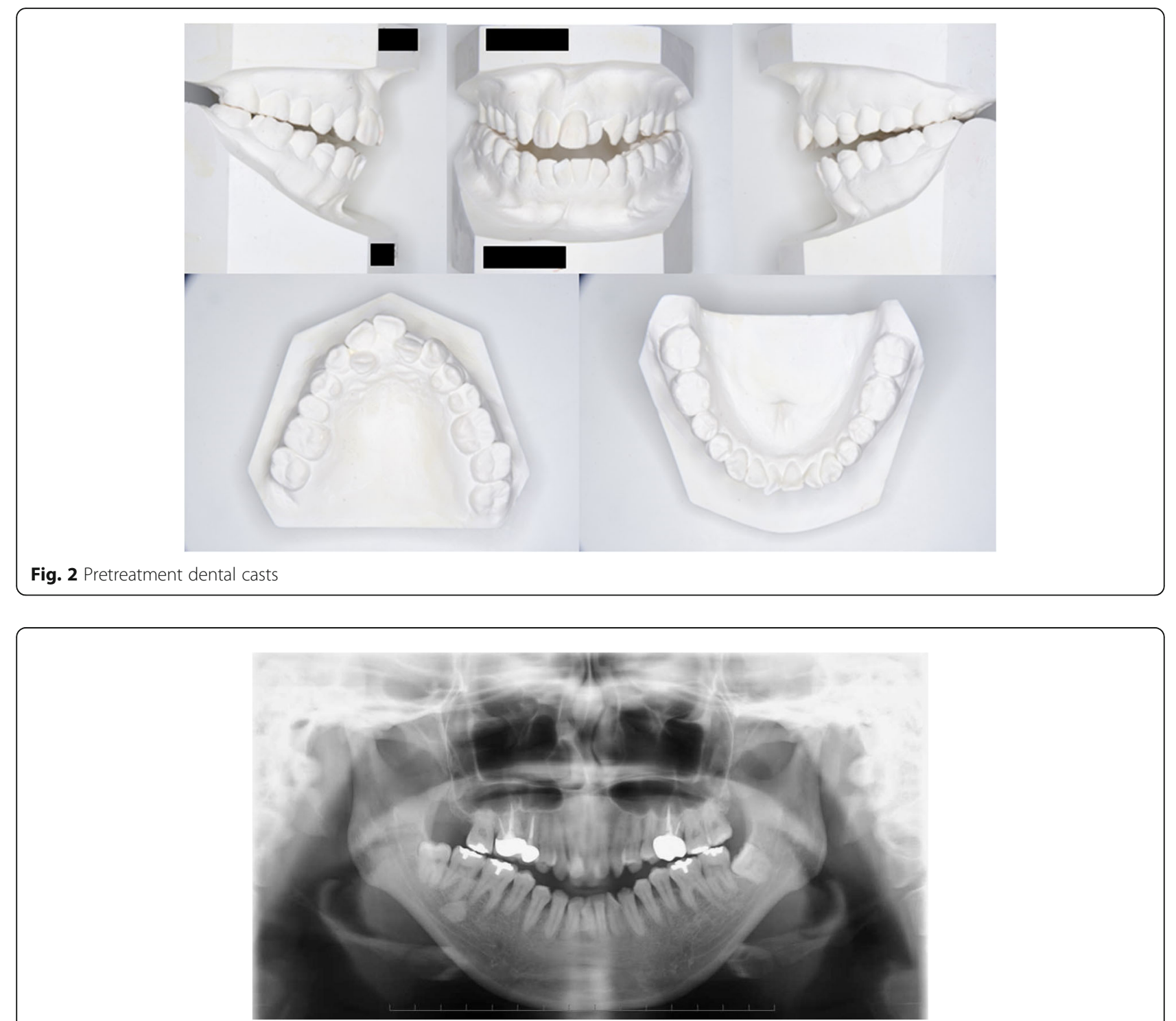

Fig. 3 Pretreatment panoramic radiograph

Table 1 Summary of cephalometric measurements

\begin{tabular}{lcc}
\hline Measurements & Pre-treatment & Post-treatment \\
\hline SNA $\left(^{\circ}\right)$ & 80.0 & 79.3 \\
SNB $\left(^{\circ}\right)$ & 68.4 & 68.8 \\
ANB $\left(^{\circ}\right)$ & 11.5 & 10.1 \\
FMA $\left(^{\circ}\right)$ & 47.5 & 46.5 \\
FMIA $\left(^{\circ}\right)$ & 40.5 & 53.2 \\
IMPA $\left(^{\circ}\right)$ & 92.0 & 80.3 \\
U1-FH $\left(^{\circ}\right)$ & 104.6 & 96.2 \\
Over jet $(\mathrm{mm})$ & 3.5 & 1.5 \\
Over bite $(\mathrm{mm})$ & -6.0 & 1.5 \\
\hline
\end{tabular}

$S N A$ angle of sella-nasion-point $A, S N B$ angle of sella-nasion-point $B$, $A N B$ angle of point A-nasion-point $B, F M A$ Frankfort-mandibular plane angle, FMIA Frankfort-mandibular incisor angle, IMPA incisor mandibular plane angle, U1-FH upper incisor-Frankfort plane angle, $\left(^{\circ}\right.$ ) measurement of a plane angle
Top Auto Screw; Jeil Medical Corp., South Korea) into the palatal region of the maxillary first molar, under local anesthesia, to intrude the maxillary posterior teeth. A transpalatal arch was also placed in order to maintain the maxillary molar width (Fig. 6). The molars were connected by an elastic chain to intrude them and to avoid the loss of anchorage. Distal movement of the maxillary canines and mandibular first premolar was then initiated.

After 24 months, the extraction spaces of premolars had closed. The maxillary dental midline had shifted to the right by $3 \mathrm{~mm}$. However, the left canine and molar relationship continued to be class II, while the right side had nearly progressed to a class I relation (Fig. 7). Hence, the maxillary left first molar was 

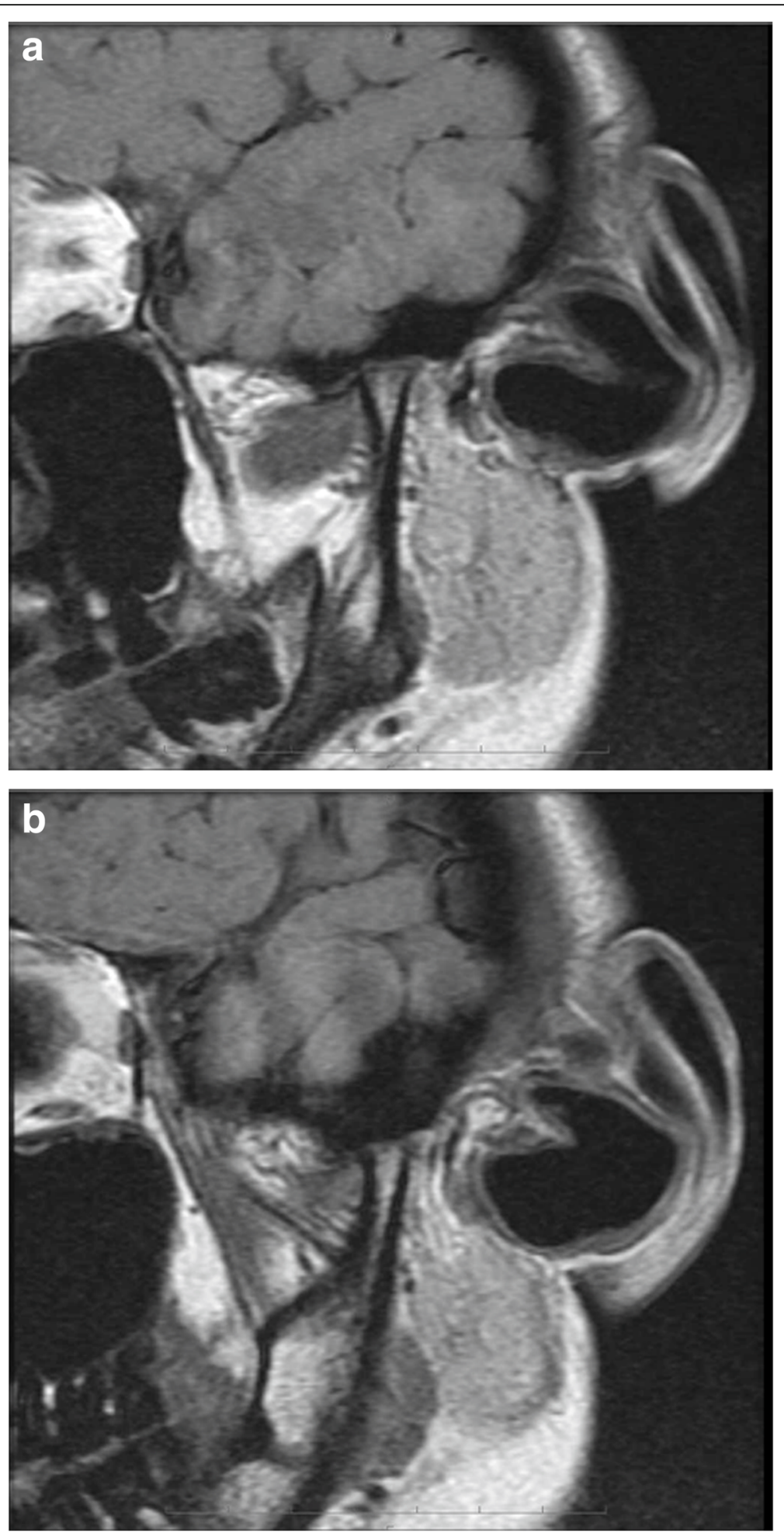

Fig. 4 Pretreatment magnetic resonance imaging. a Right side; b left side 


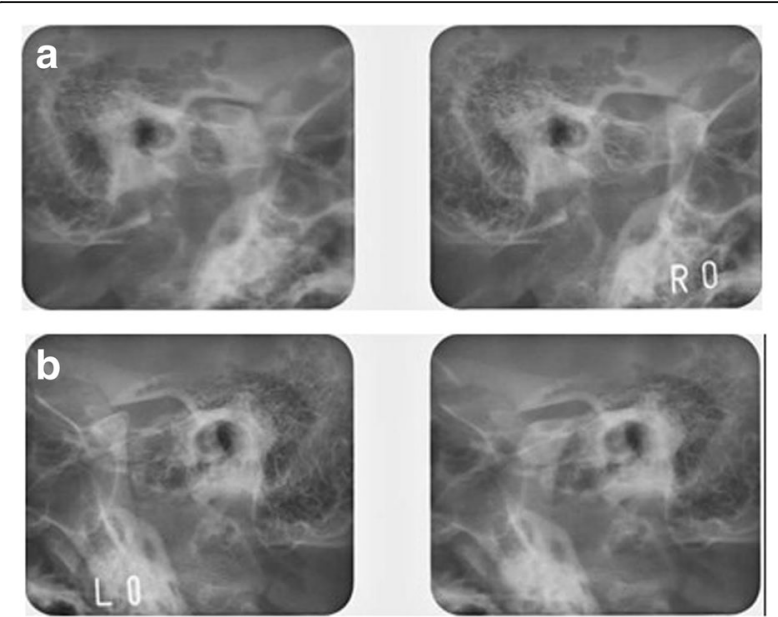

Fig. 5 Pretreatment Schüller's view. a Right side central occlusion and open; $\mathbf{b}$ left side central occlusion and open

extracted to correct the midline and the left molar relationship. The maxillary left premolars were moved distally using a miniscrew $(1.6 \mathrm{~mm}$ in diameter and 8 $\mathrm{mm}$ in length) which was inserted into the maxillary left buccal alveolar bone.

After 36 months, the anterior open bite was corrected to $1.5 \mathrm{~mm}$ and the teeth had attained a class I molar relationship (Figs. 8 and 9). All the orthodontic appliances and miniscrews were then removed, and lingual bonded retainers were affixed on both arches. In addition, a Begg-type retainer with tongue crib was also affixed in the maxilla to avoid tongue thrust. Our patient did not have any TMD symptoms during the active treatment and the retention period. The

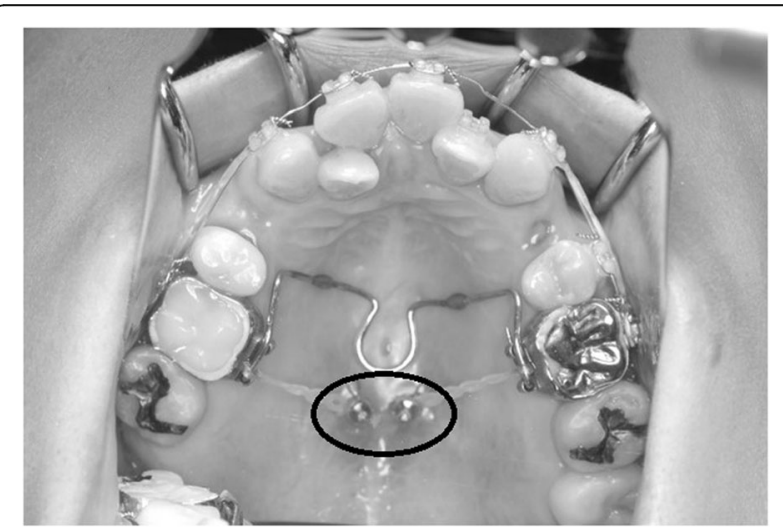

Fig. 6 Intrusion of the molars by elastic chain. A circle shows miniscrews occlusion continued to be stable at 24 months from the initiation of the retention.

\section{Treatment results}

After orthodontic treatment, the overbite increased to $1.5 \mathrm{~mm}$, while the molar and canine relationships changed to class I on both sides. The maxillary and mandibular dental midlines coincided, and the arch alignment was well corrected. There was no major variation in the posttreatment facial profile compared with the pretreatment profile. Although, the posttreatment panoramic radiograph suggested minor root resorption of the maxillary incisors, all roots were aligned in parallel (Fig. 10). On the cephalometric pretreatment and posttreatment superimposition, the upper and lower anterior teeth were distalized by 5 $\mathrm{mm}$ and $3 \mathrm{~mm}$, respectively, and extruded by $2 \mathrm{~mm}$ and $3 \mathrm{~mm}$, respectively. The maxillary molars were intruded by $1 \mathrm{~mm}$ (Fig. 11). The ANB angle had changed from $11.5^{\circ}$ to $10.1^{\circ}$, and the FMA had changed from $47.5^{\circ}$ to $46.5^{\circ}$ (Table 1). Posttreatment Schüller's view revealed no change in condyle shape and jaw movement (Fig. 12a, b). Our patient did not experience any symptoms of TMD, such as pain on mouth opening, during the orthodontic treatment.

\section{Discussion}

The TMJ disc in patients with DDwoR is shifted anteriorly and cannot revert to the correct position during jaw movement, resulting in TMJ pain and limitation of jaw movement [23]. Numerous treatment methods have been tried for managing DDwoR including manipulation, internal medicine [24], and surgical correction [25]. Although the exact mechanism of the occlusal splint is not clear [26], it is one of the important and frequently used treatment modalities. It has been suggested that splint therapy may reduce overloading on the TMJ and relieve the masticatory muscles [24]. A 2-year follow-up study suggested that splint therapy effectively improved the maximum mouth opening and alleviated pain associated with DDwo R [27]. The study by Stiesch-Scholz et al. also suggested that stabilization and pivot splints improved maximum mouth opening and reduced TMJ pain related to DDwoR [28].

In this case, our patient was diagnosed as having DDwoR via MRI, and a stabilization occlusal splint was used before orthodontic treatment to reduce the TMJ pain associated with masticatory movement. As a result of splint therapy for 3 months, the TMJ pain associated with chewing and mouth opening was relieved. There were no symptoms of TMD during the active orthodontic treatment and the retention period. Schüller's view also revealed that there was no change of condyle shape and jaw movement 


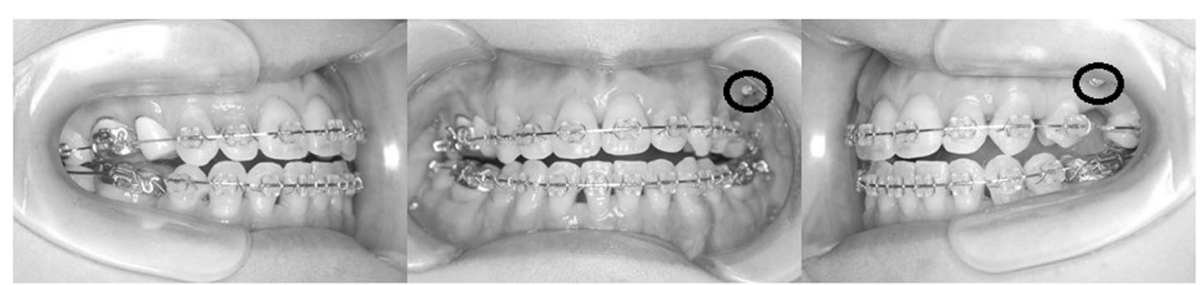

Fig. 7 Intraoral photographs during treatment (after extraction of the upper left first molar, a circle shows a miniscrew)

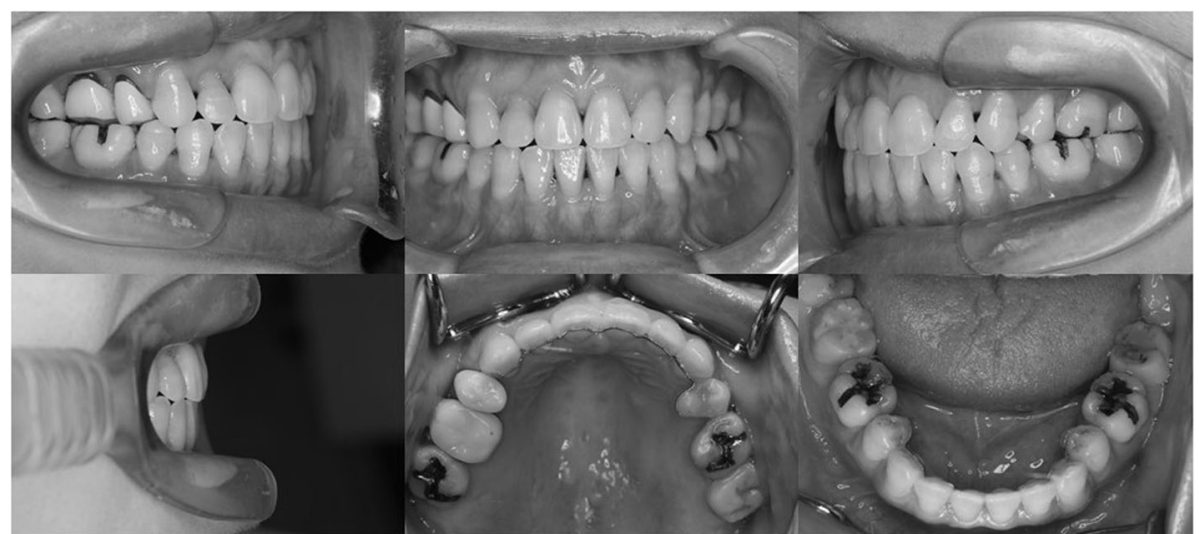

Fig. 8 Posttreatment intraoral photographs

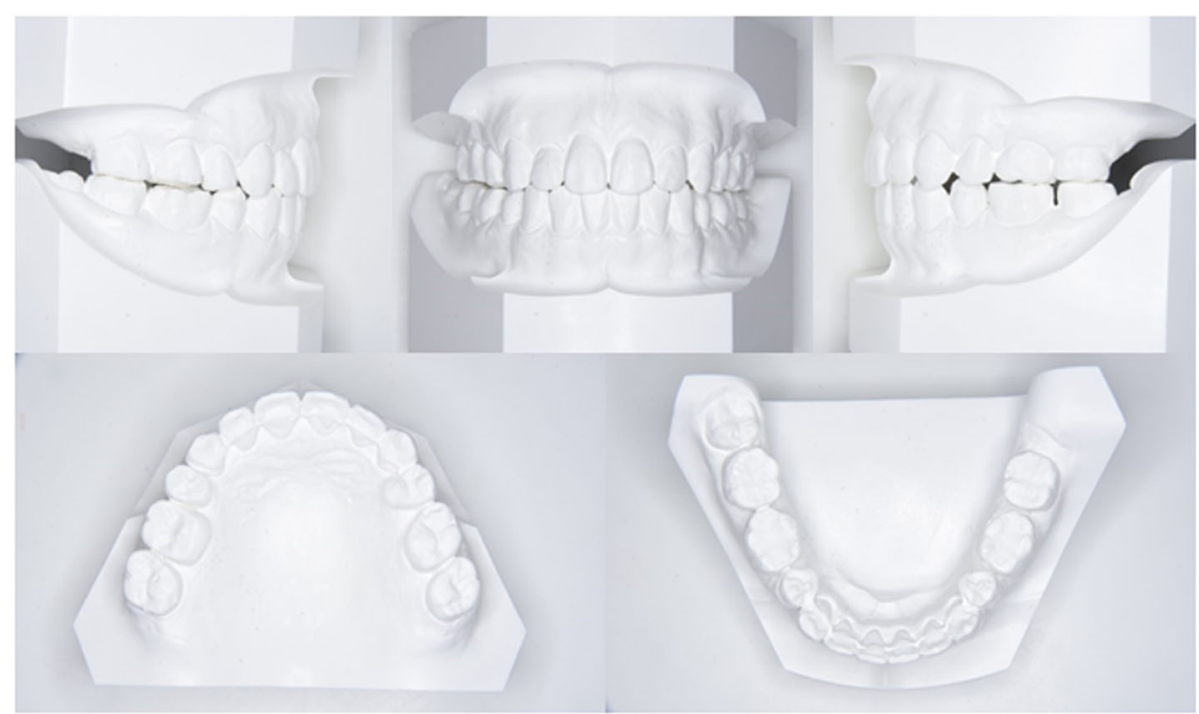

Fig. 9 Posttreatment dental casts 


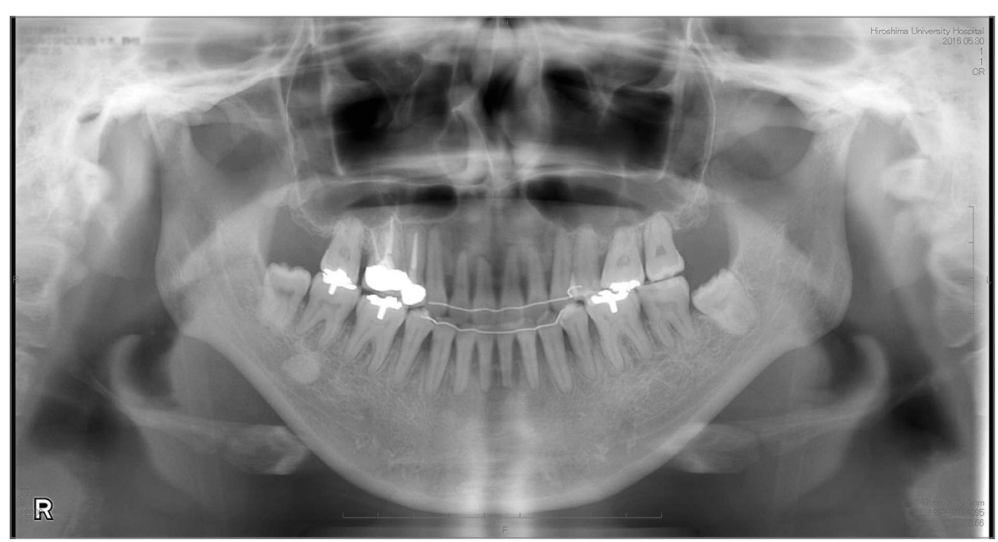

Fig. 10 Posttreatment panoramic radiograph

before and after orthodontic treatment. However, a recent study showed that splint therapy can be continued during the first several months with orthodontic treatment by adjustment of the splint according to the tooth movement [29]. So, simultaneous recovery in the TMJ with the orthodontic treatment might be achieved without delay of the treatment in this case.

Anterior open bite can occur following overgrowth of the posterior dentoalveolar heights in the maxilla and mandible. Orthognathic surgery is considered effective in improving occlusion and facial profile in patients with severe skeletal open bite along with excessive lower facial height. In such cases, maxillary surgical impaction is often applied for the mandibular counterclockwise rotation. Le Fort I and bilateral sagittal split ramus osteotomy (SSRO) reportedly offer successful and stable outcomes in patients with skeletal open bite [30]. Hoppenreijs et al. reported that Le Fort I osteotomy with or without bilateral SSRO exhibited good skeletal stability in patients with skeletal anterior open bites [31]. In the present case, our patient showed a severe anterior open bite with DDwoR. Because Aghabeigi et al. reported that orthognathic surgery did not have any effect on TMD in patients with anterior open bite [32], and we

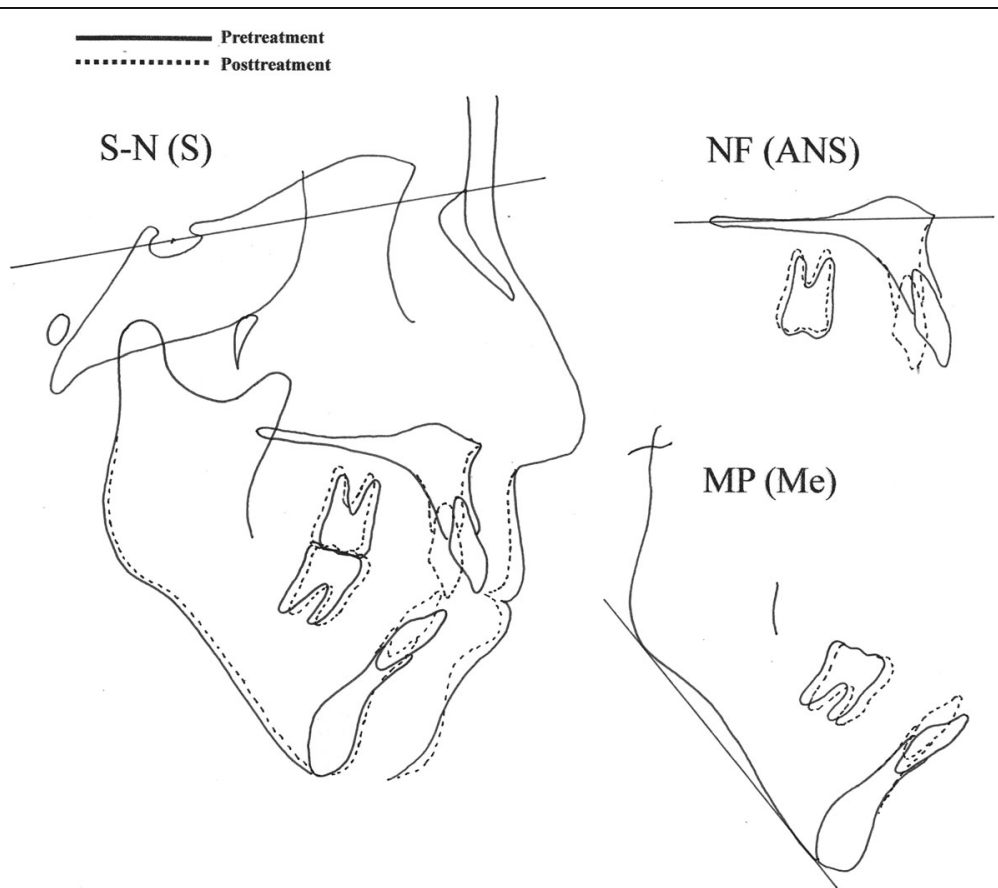

Fig. 11 Cephalometric superimposition (pretreatment and posttreatment). MP (Me) superimposition for mandibular plane at menton, NF (ANS) superimposition for nasal floor at anterior nasal spine, S-N (S) superimposition for sella-nasion at sella 


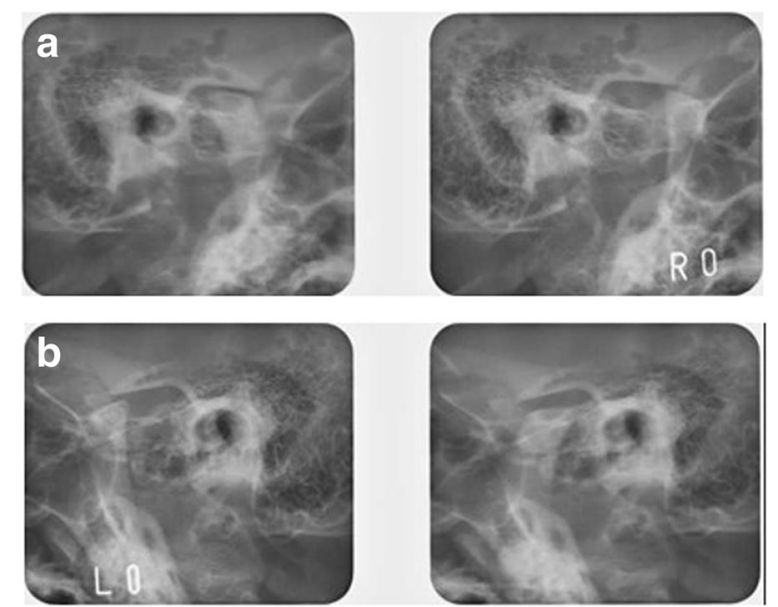

Fig. 12 Posttreatment Schüller's view. a Right side central occlusion and open; $\mathbf{b}$ left side central occlusion and open

wanted to reduce the burden on TMJ induced by orthognathic surgery, an orthodontic camouflage treatment was chosen in this patient. However, Thilander et al. suggested that orthognathic surgery was effective in improving the symptoms of TMD [33]; study of the role of orthognathic surgery in the management of TMD should be progressed.

A previous study showed that molar intrusion by miniscrew anchorage was an effective treatment option in patients with TMD who have horizontal open bite with a steep mandible [20]; hence, this option was chosen in the current study to correct the anterior open bite via orthodontic treatment using miniscrew anchorage. Xun et al. showed that miniscrews can intrude both upper and lower molars by an average of $1.8 \mathrm{~mm}$ and $1.2 \mathrm{~mm}$ respectively which leads to a counterclockwise rotation of the mandible [34]. In the present case, the maxillary molars were intruded by $1 \mathrm{~mm}$ and FMA decreased by $0.8^{\circ}$. However, since the change was negligible, improvement of the overbite was brought about by extrusion of both maxillary and mandibular incisors.

A right shift in the maxillary dental midline was noted after the premolar extraction space was closed, while the left canine and molar relationship remained class II. Hence, the maxillary left first molar was extracted. In such cases, the third molar is removed and the second and first molars are moved distally to achieve a class I molar relationship. However, molar distalization requires more time and out patient's left first molar was pulpless and was restored by a fullcast crown. Moreover, the left third molar was intact and the size was appropriate. Hence, it was decided to extract the first molar to correct the midline and left molar relationship. As a result, a good intercuspal relationship with a normal overjet and overbite were achieved and the maxillary and mandibular midlines coincided. However, since long-term stability of open bite correction depends on many factors, such as tongue thrust, periodic checkups and examinations of the TMJ are necessary for this patient.

\section{Conclusions}

1. Severe open bite with a class II molar relationship can be treated with miniscrews and molar extraction.

2. Occlusal splint therapy and orthodontic treatment are useful for managing patients with DDwoR.

3. The authors have no conflicts of interest directly relevant to the content of this article.

\section{Abbreviations}

ANB: Angle of point A-nasion-point B; DDwoR: Anterior disc displacement without reduction; FMA: Frankfort-mandibular plane angle; MRI: Magnetic resonance imaging; SSRO: Sagittal split ramus osteotomy;

TMD: Temporomandibular joint disorder; TMJ: Temporomandibular joint

\section{Acknowledgements}

The authors thank all the staff of the Department of Orthodontics and

Craniofacial Developmental Biology, Hiroshima University Graduate School of Biomedical \& Health Sciences.

\section{Authors' contributions}

MK designed the study. The patient was treated by MK and YY. MK and KT wrote the article. YY, JI, HK, and KI analyzed the data. All authors read and approved the final manuscript.

\section{Funding}

No external funding was utilized to support publication of this article.

Availability of data and materials

Not applicable.

Ethics approval and consent to participate Not applicable.

\section{Consent for publication}

Written informed consent was obtained from the patient for publication of this case report and any accompanying images. A copy of the written consent is available for review by the Editor-in-Chief of this journal.

\section{Competing interests}

The authors declare that they have no competing interests.

Received: 18 June 2018 Accepted: 27 May 2019

Published online: 07 July 2019

\section{References}

1. Mcneil C. History and evolution of TMD concepts. Oral Sur Oral Med Oral Pathol Oral Radiol Endod. 1997;83:51-60.

2. Pereira LI, Costa RC, Franca JP, Pereira SM, Castelo PM. Risk indicators for signs and symptoms of temporomandibular dysfunction in children. J Clin Pediatr Dent. 2009;34:81-6.

3. Sakuda M, Tanne K, Tanaka E, Takasugi H. An analytic method for evaluating condylar position in the TMJ and its application to orthodontic patients with painful clicking. Am J Orthod Dentofac Orthop. 1992;101:88-96.

4. Buschang PH, Sankey W, English JD. Early treatment of hyperdivergent open-bite malocclusions. Semin Orthod. 2002;8:130-40. 
5. Lopez-Gavito G, Wallen TR, Little RM, Joondeph DR. Anterior open-bite malocclusion: a longitudinal 10-years post-retention evaluation of orthodontically treated patients. Am J Orthod. 1985;87:175-86.

6. Collins MK. A nonsurgical approach to treatment of high angle class $\|_{\text {, }}$ division 1 malocclusion in a nongrowing patient. Am Jo Orthod Dentofac Orthop. 1996;110:678-81.

7. Cope JB, Sachdeva RCL. Nonsurgical correction of a class II malocclusion with a vertical growth tendency. Am J Orthod Dentofac Orthop. 1999;116: 66-74.

8. Proffit WR. Contemporary Orthodontics. 2nd ed. St Louis: Mosby Year Book; 1993. p. 236-7.

9. Sugawara J, Daimaruya T, Umemori M, Nagasaka H, Takahashi I, Kawamura $\mathrm{H}$, et al. Distal movement of mandibular molars in adult patients with skeletal anchorage system. Am J Orthod Dentofac Orthop. 2004;125:130-8.

10. Umemori M, Sugawara J, Mitani H. Skeletal anchorage system for open-bite correction. Am J Orthod Dentofac Orthop. 1999;115:166-74

11. Erverdi N, Keles A, Nanda R. The use of skeletal anchorage in open bite treatment: a cephalometric evaluation. Angle Orthod. 2004;74:381-90.

12. Sherwood KH, Burch JG, Thompson WJ. Closing anterior open bites by intruding molars with titanium miniplate anchorage. Am J Orthod Dentofac Orthop. 2002:122:593-600.

13. Costa A, Raffaini M, Melsen B. Miniscrews as orthodontic anchorage: a preliminary report. Int J Adult Orthod Orthognath Surg. 1998;13:201-9.

14. Kanomi R. Mini-implant for orthodontic anchorage. J Clin Orthod. 1997; 31:763-7.

15. Park HS, Bae SM, Kyung HM, Sung JH. Micro-implant anchorage for treatment of skeletal Class 1 bialveolar protrusion. J Clin Orthod. 2001; 35:417-22.

16. Paik $\mathrm{CH}$, Woo YJ, Boyd R. Treatment of an adult patient with vertical maxillary excess using miniscrew fixation. J Clin Orthod. 2003:37:423-8.

17. Xun $\mathrm{CL}$, Zeng $\mathrm{XL}$, Wang $X$. Clinical application of miniscrew implant for maximum anchorage treatment. Chin J Stomatol. 2004:39:505-8.

18. Xun $\mathrm{CL}$, Zeng $\mathrm{XL}$, Wang $X$. Clinical application of miniscrew implant anchorage for anterior teeth intrusion treatment. Chin J Orthod. 2004;11:29-32.

19. Kuroda S, Sugawara Y, Tamamura N, Takano-Yamamoto T. Anterior open bite with temporomandibular disorder treated with titanium screw anchorage: evaluation of morphological and functional improvement. Am J Orthod Dentofac Orthop. 2007:131:550-60.

20. Kaku M, Koseki H, Kawazoe A, Abedini S, Kojima S, Motokawa M, et al. Treatment of case of skeletal class II malocclusion with temporomandibular joint disorder using miniscrew anchorage. Cranio. 2011;29:155-63.

21. Tanaka E, Yamano E, Inubushi T, Kuroda S. Management of acquired open bite associated with temporomandibular joint osteoarthritis using miniscrew anchorage. Korean J Orthod. 2012;42:144-54.

22. Yanagita T, Adachi R, Kamioka H, Yamashiro T. Severe open bite due to traumatic condylar fractures treated nonsurgically with implanted miniscrew anchorage. Am J Orthod Dentofac Orthop. 2013;143:137-47.

23. Dimitroulis $\mathrm{G}$. The prevalence of osteoarthrosis in cases of advanced internal derangement of the temporomandibular joint: a clinical, surgical and histological study. Int J Oral Maxillofac Surg. 2005;34:345-9.

24. Okeson JP. Joint intracapsular disorders: diagnostic and nonsurgical management considerations. Dent Clin N Am. 2007;51:85-103.

25. Dimitroulis G, McCullough M, Morrison W. Quality-of-life survey comparing patients before and after discectomy of the temporomandibular joint. J Oral Maxillofac Surg. 2010;68:101-6.

26. Dao TT, Lavigne GJ. Oral splints: the crutches for temporomandibular disorders and bruxism? Crit Rev Oral Biol Med. 1998:9:345-61.

27. Kai S, Kai H, Tabata O, Shiratsuchi Y, Ohisi M. Long-term outcomes of nonsurgical treatment in nonreducing anteriorly displaced disk of the temporomandibular joint. Oral Surg Oral Med Oral Pathol Oral Radiol Endod. 1998:85:258-67.

28. Stiesch-Scholz M, Kempert J, Wolter S, Tschernitschek H, Rossbach A Comparative prospective study on splint therapy of anterior disc displacement without reduction. J Oral Rehabil. 2005:32:474-9.

29. Mitsui SN, Yause A, Kuroda S, Tanaka E. Long-term stability of conservative orthodontic treatment in a patient with temporomandibular joint disorder. J Orthod Sci. 2016;5:104-8.

30. Ding Y, Xu TM, Lohrmann B, Gellrich NC, Schewestaka-Polly R. Stability following combined orthodontic-surgical treatment for skeletal anterior open bite - a cephalometric 15-year follow-up study. J Orofac Orthop. 2007; 68:245-56.
31. Hoppenreijs TJ, Frihofer HP, Stoelinga PJ, Tuinzing DB, van't Hof MA, van der Linden FP, et al. Skeletal and dento-alveolar stability of Le Fort I intrusion osteotomies and bimaxillary osteotomies in anterior open bite deformities. A retrospective three-centre study. Int J Oral Maxillofac Surg. 1997;26:161-75.

32. Aghabeigi B, Hiranaka D, Keith DA, Kelly JP, Crean SJ. Effect of orthognathic surgery on the temporomandibular joint in patients with anterior open bite. Int J Adult Orthod Orthognath Surg. 2001;16:153-60.

33. Thilander B, Rubio G, Pena L, de Mayorga C. Prevalence of temporomandibular dysfunction and its association with malocclusion in children and adolescents: an epidemiologic study related to specified stages of dental development. Angle Orthod. 2002;72:146-54.

34. Xun C, Zeng X, Wang X. Microscrew anchorage in skeletal anterior openbite treatment. Angle Orthod. 2007;77:47-56.

\section{Publisher's Note}

Springer Nature remains neutral with regard to jurisdictional claims in published maps and institutional affiliations.
Ready to submit your research? Choose BMC and benefit from:

- fast, convenient online submission

- thorough peer review by experienced researchers in your field

- rapid publication on acceptance

- support for research data, including large and complex data types

- gold Open Access which fosters wider collaboration and increased citations

- maximum visibility for your research: over $100 \mathrm{M}$ website views per year

At $\mathrm{BMC}$, research is always in progress.

Learn more biomedcentral.com/submissions 